\title{
SIZE AND DISTENSIBILITY OF THE AORTIC ROOT AND AORTIC VALVE FUNCTION AFTER DIFFERENT TECHNIQUES OF THE ROSS PROCEDURE
}

Claudia Schmidtke, MD

J. F. Matthias Bechtel, MD

Michael Hueppe, $\mathrm{PhD}^{\mathrm{b}}$

Axel Noetzold, MD

Hans-Hinrich Sievers, MD, FETCS ${ }^{\text {a }}$
Objectives: In the Ross procedure, 3 different techniques are used for aortic valve replacement with the pulmonary autograft: freestanding root, inclusion, and subcoronary implantation. The objective of this study was to evaluate echocardiographically the influence of the particular operative technique on dimension, distensibility, and valve function.

Methods: Between February 1990 and August 1998, the Ross procedure was performed in 111 patients (mean age, $48.6 \pm 14.1$ years; range, 15.2-70.6 years), with 1 early and 1 late death, 1 autograft replacement, and 1 patient lost to follow-up. The remaining patients underwent the freestanding root ( $\mathrm{n}=9$ patients), inclusion $(\mathrm{n}=14$ patients), and subcoronary techniques $(\mathrm{n}=$ 84 patients). Echocardiography was performed at a mean follow-up of $26 \pm$ 21.3 months after operation and was compared with the echocardiographic findings of the control subjects ( $n=10$ subjects). Root sizes were measured at the level of the anulus, sinus, and supra-aortic ridge; the distensibility was calculated as pressure strain elastic modulus and percent change of radius.

Results: Size and distensibility of the aortic root were normal, except for a larger diameter at the sinus level in the root technique in comparison to the subcoronary technique $(P<.05$; maximum diameter, $41.3 \pm 8.6 \mathrm{~mm}$ vs 32.6 $\pm 4.0 \mathrm{~mm}$ ). Aortic valve function was comparable among groups with low pressure gradients and most patients with no or trace aortic insufficiency.

Conclusions: The freestanding root, inclusion, and subcoronary techniques in the Ross procedure provide comparable excellent hemodynamics, normal root size, and distensibility, except for the enlarged sinus diameter in the freestanding root. These results may have some impact on the operative procedure and follow-up investigations. ( $\mathrm{J}$ Thorac Cardiovasc Surg 2000;119:990-7)
$T^{1}$ he first studies on autografts as a substitute for the aortic valve date back to 1960 and 1964, when Lower and colleagues ${ }^{1}$ and Pillsbury and Shumway ${ }^{2}$ in animal experiments transferred the autologous pulmonary valve into the ascending aorta or aortic root. In 1967, Ross $^{3}$ reported the first successful clinical use of the autograft for aortic valve replacement. After land-

From the Departments of Cardiac Surgery a and Anesthesiology, Medical University of Luebeck, Luebeck, Germany.

Received for publication June 28, 1999; revisions requested Aug 23, 1999; revisions received Nov 18, 1999; accepted for publication Dec 15, 1999.

Address for reprints: Prof $\mathrm{Dr}$ med H-H. Sievers, Klinik für Herzchirurgie, Medizinische Universität zu Luebeck, Ratzeburger Allee 160, D - 23538 Luebeck, Germany (E-mail: schmidtk@medinf.mu-luebeck.de).

Copyright (C) 2000 by The American Association for Thoracic Surgery

$0022-5223 / 2000 \$ 12.00+0 \quad \mathbf{1 2 / 1 / 1 0 5 2 1 0}$

doi: $10.1067 / \mathrm{mtc} .2000 .105210$

990 mark reports on the excellent results after the Ross procedure, ${ }^{4,5}$ increasing numbers of surgeons have used this technique for the surgical treatment of the diseased aortic valve. The original subcoronary implantation technique, which may involve the risk of valve failure because of technical malpositioning 6 and size mismatch, was abandoned in favor of the inclusion method ${ }^{7}$ and the freestanding root technique ${ }^{8}$ to preserve the anatomical unit of the root, warranting optimal hemodynamics. Freestanding root is now the preferred operative technique. Potential problems of this method relate to the impact of sudden exposure of the pulmonary root to systemic pressure. The resulting overstress to the valve structures may cause geometric, functional, and histologic changes of the tissue, thereby interfering with the elastic properties of the root. These characteristics possibly have important implications on valve function, on stress distribution of the leaflets, and, presumably, on the fate of the autograft, and they have 
Table I. Preoperative clinical and operative data

\begin{tabular}{|c|c|c|c|c|c|}
\hline & \multicolumn{4}{|c|}{ Group } & \multirow[b]{2}{*}{$\mathrm{P}$ value } \\
\hline & $\begin{array}{c}A \\
\text { (freestanding root) }\end{array}$ & $\begin{array}{c}B \\
\text { (inclusion) }\end{array}$ & $\begin{array}{c}C \\
\text { (subcoronary) }\end{array}$ & $\begin{array}{c}D \\
\text { (control) }\end{array}$ & \\
\hline Patients (n) & 9 & 14 & 84 & 10 & \\
\hline $\operatorname{Sex}(M / F)$ & $9 / 0$ & $10 / 4$ & $64 / 20$ & $6 / 4$ & $>.2$ \\
\hline Age at operation (y) & $42.5 \pm 16.0(35.2)$ & $51.4 \pm 12.6(56.7)$ & $49.2 \pm 14.0(52.8)$ & - & $>.2$ \\
\hline Age at examination (y) & $49.1 \pm 16.5(39.1)$ & $54.2 \pm 12.7(59.1)$ & $50.8 \pm 14.2(54.8)$ & $41.7 \pm 16.1(38.0)$ & $>.2$ \\
\hline Follow-up (mo) & $79.3 \pm 17.8(83.0)$ & $33.4 \pm 5.1(33.7)$ & $19.1 \pm 13.3(19.2)$ & - & $\begin{array}{c}<.001 \\
\left({ }^{*} \mathrm{~A}>\mathrm{B}, \mathrm{C} ;{ }^{*} \mathrm{~B}>\mathrm{C}\right)\end{array}$ \\
\hline AI (no/yes; \%) & $6 / 3(33.3)$ & $10 / 4(28.6)$ & $62 / 22(26.2)$ & - & $>.2$ \\
\hline AS (no/yes; \%) & 8/1 (11.1) & $13 / 1(7.1)$ & 70/14 (16.7) & - & $>.2$ \\
\hline $\mathrm{AI}+\mathrm{AS}(\mathrm{no} / \mathrm{yes} ; \%)$ & $4 / 5(55.6)$ & $5 / 9(64.3)$ & $36 / 48(57.1)$ & - & $>.2$ \\
\hline AV-PG (mm Hg) & $68 \pm 32(81.5)$ & $105 \pm 17(105)$ & $70 \pm 29(70.0)$ & - & $\begin{array}{c}.001 \\
\left({ }^{*} \mathrm{~B}>\mathrm{A}, \mathrm{C}\right)\end{array}$ \\
\hline BAV (no/yes) & $9 / 0$ & $9 / 5$ & $46 / 32$ & $10 / 0$ & .053 \\
\hline $\operatorname{BSA}\left(m^{2}\right)$ & $2.0 \pm 0.2(1.9)$ & $1.9 \pm 0.1(1.9)$ & $2.1 \pm 1.6(2.0)$ & $2.0 \pm 0.2(1.9)$ & $>.2$ \\
\hline NYHA (median) & 2.0 & 2.5 & 2.5 & - & $>.2$ \\
\hline $\mathrm{EF}(\%)$ & $67.0 \pm 8.4(68)$ & $63.0 \pm 12.2(62)$ & $69.0 \pm 9.6(70)$ & - & .18 \\
\hline $\begin{array}{l}\text { Bypass time (min; } \\
\text { mean } \pm \mathrm{SD} ; \text { median) }\end{array}$ & $154.0 \pm 30.9(150)$ & $203.0 \pm 21.6(200)$ & $209.0 \pm 28.5(204)$ & - & $\begin{array}{c}<.001 \\
\left({ }^{*} \mathrm{~A}<\mathrm{B}, \mathrm{C}\right)\end{array}$ \\
\hline $\begin{array}{l}\text { Ischemic time (min; } \\
\text { mean } \pm \mathrm{SD} ; \text { median) }\end{array}$ & $105.0 \pm 21.1(105)$ & $151.0 \pm 16.4(146)$ & $152.0 \pm 23.2(150)$ & - & $\begin{array}{c}<.001 \\
\left({ }^{*} \mathrm{~A}<\mathrm{B}, \mathrm{C}\right)\end{array}$ \\
\hline
\end{tabular}

$A I$, Aortic valve insufficiency; $A S$, aortic valve stenosis; $A I+A S$, combined aortic valve disease; $A V-P G$, instantaneous pressure gradient across the aortic valve; $B A V$, bicuspid aortic valve; BSA, body surface area; NYHA, New York Heart Association classification; $E F$, ejection fraction of left ventricle (levocardiogram).

$* P<.05$, other possible pair comparisons were nonsignificant.

not been studied before. Therefore, the purpose of this study was to evaluate echocardiographically the influence of the particular implantation technique of the autograft on size, distensibility, and valve function.

\section{Methods}

Patients. Between February 1990 and August 1998, 111 patients with aortic valve disease underwent 3 different techniques of aortic valve replacement with pulmonary autografts. Initially, the freestanding root technique was performed (group A, 9 patients) followed by the inclusion (group B, 14 patients), and the subcoronary technique (group C, 84 patients). The mean follow-up period of all patients was $26 \pm$ 21.3 months (range, 0.1-99.1 months).

One patient died in the perioperative period 10 days after operation (hospital mortality, <1\%). One patient died of esophageal bleeding 18 months after the operation. For another patient, a reoperation was necessary because of a subvalvular aneurysm 6 years after freestanding root replacement. One patient was lost to follow-up.

The control group (group D) consisted of 10 individuals in whom (by medical history, standard clinical examination, and transthoracic echocardiography) no abnormalities of the aortic valve (except for 1 patient with a mild aortic regurgitation), aortic root, or left ventricle function were observed. Patient characteristics and operative data are shown in Table I.

Exclusion criteria for the Ross procedure were severe calcification of the aortic root, reduced ejection fraction lower than $40 \%$, more than 2-vessel coronary artery disease, and anatomical or structural defects of the pulmonary valve.

Operative techniques. Standard cardiopulmonary bypass with a membrane oxygenator (Hollow Fiber Oxygenator; Spiral Gold, Baxter, Puerto Rico) at moderate hypothermia $\left(26^{\circ} \mathrm{C}\right.$ temperature nasopharyngeal) with cold crystalloid cardioplegia (St Thomas' Hospital solution) for myocardial protection was used. The operative techniques are described in detail elsewhere. ${ }^{9}$ Briefly, in group A the proximal suture line was performed with 3-0 polypropylene continuous sutures, and the distal suture line was performed 3 to 6 millimeters apart from the supra-aortic ridge with 4-0 polypropylene continuously. In groups $\mathrm{B}$ and $\mathrm{C}$, the proximal suture line was performed with single 4-0 Prolene sutures (Ethicon, Inc, Somerville, NJ). In group $\mathrm{C}$, the noncoronary sinus was left intact. Reduction annuloplasties were performed whenever necessary to neutralize for size mismatch between autograft and aortic valve ring.

Echocardiographic data acquisition and measurements. Informed written consent was obtained before echocardiography. The investigative procedures were in accordance with institutional guidelines. All patients were evaluated clinically in regular intervals at our hospital.

Transthoracic echocardiograms were made with $2.5 \mathrm{MHz}$ ultrasound transducers (Hewlett-Packard Sonos 2500 system; Andover, Mass) during routine follow-up investigation and recorded on VHS videotape. A modified echocardiogram lead I was continuously recorded. Blood pressure was measured by cuff sphygmomanometry (Dinamap; Siemens, Erlangen, Germany). 


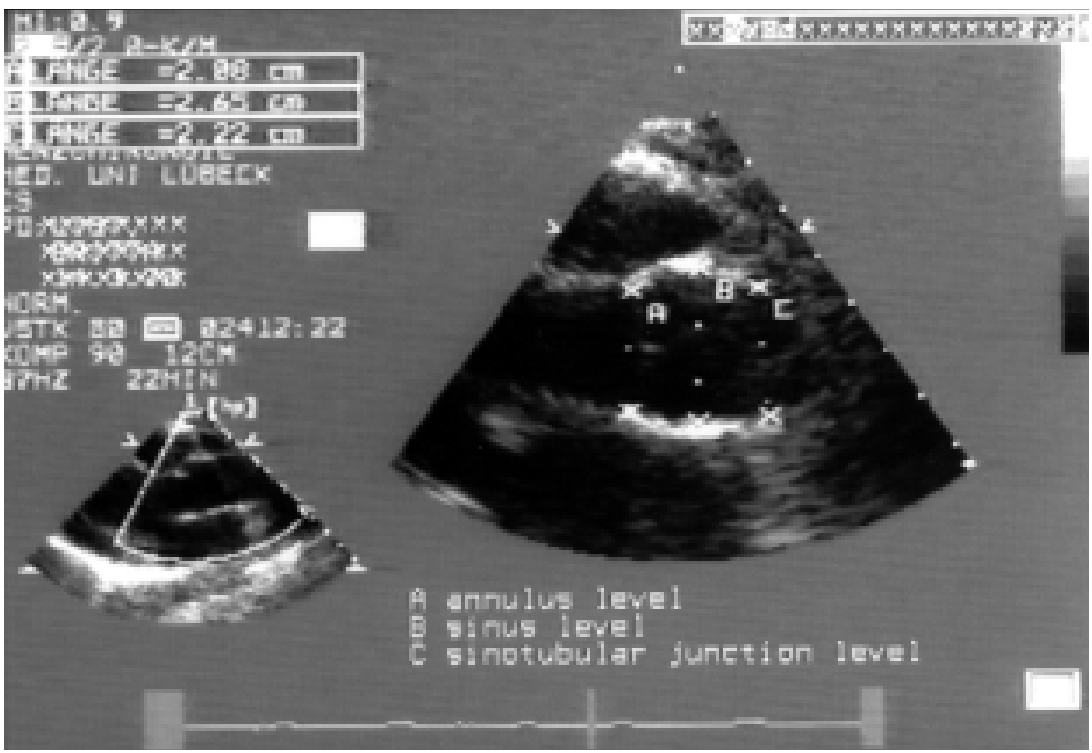

Fig 1. Transthoracic echocardiographic picture of the aortic root with indication of the level of diameter measurements.

Root dimensions were determined by 2 independent observers from video-recorded studies. The average value of 5 consecutive beats was taken. To evaluate the reproducibility of echocardiographically determined aortic root diameters at base, sinus, and supra-aortic ridge level the video-recorded studies of 5 patients were measured twice within a period of 4 weeks. The range of variation of the measured diameters was $0 \%$ to $5.6 \%$.

Two-dimensional echocardiography. The morphologic condition of the aortic cusps was examined in standard longitudinal and cross-sectional views. Autograft diameters were measured at 3 different levels: the anulus at the level of the autograft leaflet hinges, the sinus of Valsalva at the largest anteroposterior diameter, and the supra-aortic ridge level at the distal rim of the sinuses of Valsalva, as described by Roman and colleagues ${ }^{10}$ (Fig 1).

Measurements of diameters were made perpendicular to the long axis of the aorta in views that showed the largest and smallest dimensions during cardiac cycles. Left ventricular end-systolic and end-diastolic volumes were obtained from standard apical views.

Continuous-wave, pulsed, and color flow Doppler imaging. Maximum velocities across the aortic valve were obtained by continuous-wave Doppler imaging transducer. To obtain the highest velocity across the aortic valve, the 1.9$\mathrm{MHz}$ nonimaging transducer was used.

To assess aortic regurgitation, pulsed wave Doppler and color flow Doppler imaging were used for mapping the left ventricular outflow tract, and continuous spectral Doppler imaging was applied to measure the deceleration slope and pressure halftime of the aortic regurgitant jet. Trace aortic valve insufficiency was defined as a very small regurgitant jet in early diastole of a maximum of $2 \mathrm{~mm}$ in length and width and grouped to aortic valve insufficiency grade 0 . Grade I regurgitant jets (mild aortic insufficiency) were present only in the left ventricular outflow tract immediately below the valve, although grades II and III (moderate aortic insufficiency) extend to the tips of the mitral leaflets and papillary muscles, respectively. ${ }^{11}$

Calculations. The following formulas were used to calculate (1) the peak systolic pressure gradient across the aortic valve $(\Delta \mathrm{P}$; modified Bernoulli equation)

$$
\Delta \mathrm{P}[\mathrm{mm} \mathrm{Hg}]=4 \times \mathrm{v}^{2}[\mathrm{~m} / \mathrm{s}]
$$

where $\mathrm{v}$ is the peak systolic velocity across the aortic valve; (2) the percent change in radius (PCR; according to Jarmakani ${ }^{12}$ )

$$
\mathrm{PCR}[\%]=(\Delta \mathrm{R}[\mathrm{mm}] \times 100) / \mathrm{R}[\mathrm{mm}]
$$

where $\Delta \mathrm{R}$ is the difference between the largest and smallest diameter and $\mathrm{R}$ is the average diameter; and (3) the pressure strain elastic modulus (PSEM; according to Jarmakani $^{12}$ )

$$
\operatorname{PSEM}\left[\mathrm{g} / \mathrm{cm}^{2}\right]=(\Delta \mathrm{P}[\mathrm{mm} \mathrm{Hg}] \times \mathrm{R}[\mathrm{mm}]) / \Delta \mathrm{R}[\mathrm{mm}]
$$

where $\Delta \mathrm{P}$ is the difference between maximal systolic and minimal diastolic blood pressure and $\mathrm{R}$ is the average diameter.

Statistical analysis. Categoric data are given as total numbers and relative frequencies; continuous data are given as mean $\pm \mathrm{SD}$, except where otherwise stated. Because of multiple violations of conditions of parametric tests (normal distribution, homogeneity of variances) different groups were compared for each variable with the use of the KruskalWallis $H$ test. If significantly different at a level of probability that is less than .05 pairwise, post hoc comparison was achieved by means of the Mann-Whitney $U$ test with the application of Bonferroni's method for multiple pairwise 
Table II. NYHA, heart rate, cardiac output, blood pressure, and valve function

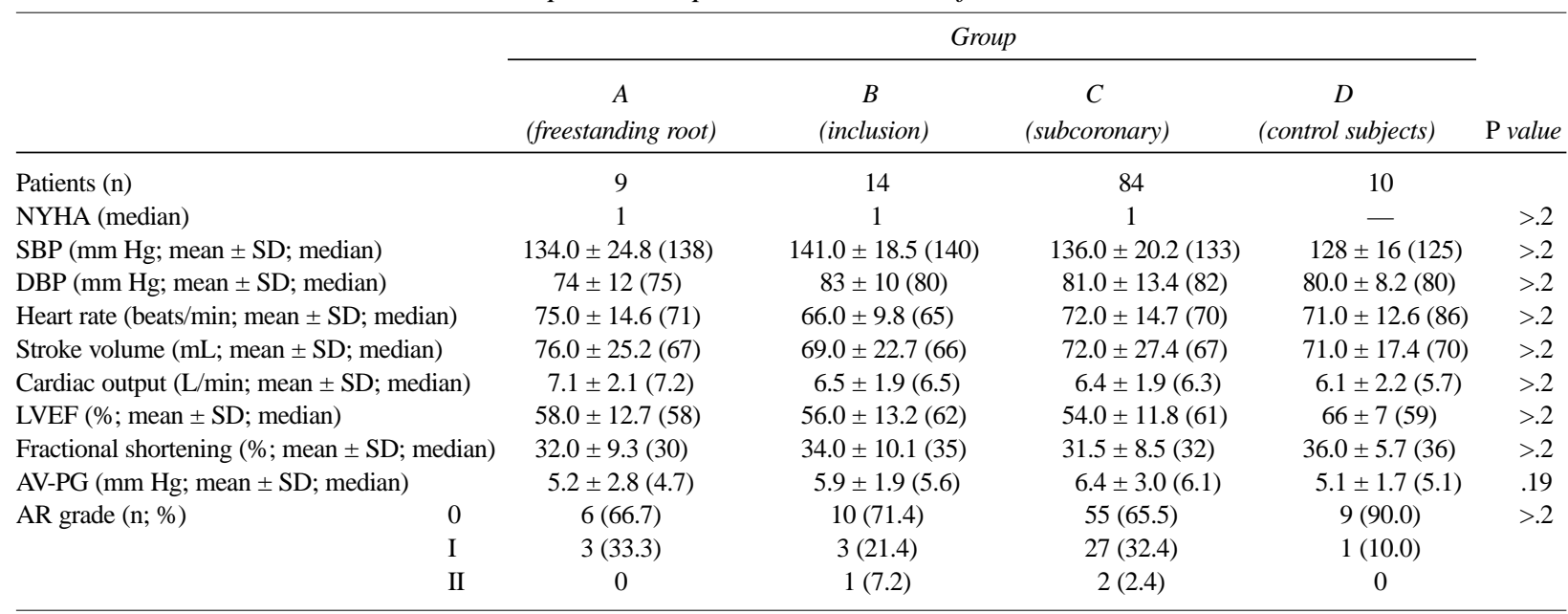

NYHA, New York Heart Association classification; $S B P$, systolic blood pressure; $D B P$, diastolic blood pressure; $L V E F$, left ventricular ejection fraction; $A V-P G$, instantaneous pressure gradient across the aortic valve; $A R$, aortic valve regurgitation.

tests. Statistical analyses were done without alpha adjustments, and therefore results are considered mainly exploratory. ${ }^{13}$ All tests were 2-sided. Statistics were performed using statistical software (SPSS for Windows 8.0; SPSS, Inc, Chicago, Ill).

\section{Results}

Hemodynamics and valve function. At postoperative examination heart rate, stroke volume, cardiac output, ejection fraction, blood pressure, and transvalvular aortic pressure gradients were comparable in groups A, $\mathrm{B}, \mathrm{C}$, and D (Table II). One hundred percent of patients in group A, $93 \%$ of patients in group B, and $98 \%$ of patients in group $\mathrm{C}$ had no or mild aortic valve regurgitation (Table II). None of the patients had more than grade II aortic regurgitation. In group D (control subjects), no aortic valve dysfunction was observed, except 1 case of mild aortic valve regurgitation.

Aortic root size. Aortic root diameters at anulus and supra-aortic ridge level were comparable between the groups (Table III). At sinus level, compared with the subcoronary group, there was a significantly increased diameter in the patients with a freestanding root (Fig 2). In 6 of 8 patients with a freestanding root, there was no dilatation at sinus level above the normal range (mean \pm 2SD). However, diameters of more than $49 \mathrm{~mm}$ were measured in 2 patients. The range for the maximum diameter at this level was 29.1 to $55.3 \mathrm{~mm}$ (Fig 3). There was no correlation of sinus diameter and time interval between operation and restudy in group A (Fig 4).

Aortic root distensibility. The cyclic change in radius and pressure strain elastic modulus as parameters of distensibility of the aortic root are listed in Table
III. No significant differences of distensibility were found at any level among groups.

\section{Discussion}

Recent reports indicate that the Ross procedure yields excellent results in most patients. ${ }^{4,5}$ Long-term survival statistics are good, with hemodynamic superiority as compared with any other replacement device, be it mechanical or bioprosthetic. In a larger series, Chambers and colleagues ${ }^{14}$ showed an $85 \%$ survival rate at 10 years and a $61 \%$ survival rate after 20 years. Freedom from autograft replacement was $88 \%$ and $75 \%$, respectively, and freedom from the replacement of the pulmonary homograft was $89 \%$ and $80 \%$, respectively. In almost all these patients, the subcoronary technique was used. In 1989, Stelzer and colleagues ${ }^{4}$ introduced the freestanding root technique as the routine procedure of the Ross operation. The advantage of this technique includes the preservation of root anatomy, minimizing the risk of malfunctioning because of surgical manipulation. However, a potential problem relates to the dimensional behavior of the neoaortic root that is subjected to systemic pressure. Sievers and colleagues ${ }^{15}$ did not observe progressive dilatation of the freestanding aortic root at the supraaortic ridge level 21 months after the operation. In longer term follow-up studies, there was, however, some kind of dilatation of the freestanding root, especially in patients with bicuspid valves. ${ }^{16}$ In our series we measured a significantly increased diameter at the sinus level in the freestanding root compared with the subcoronary technique only, now more than 70 months 
Table III. Aortic root sizes and distensibility

\begin{tabular}{|c|c|c|c|c|c|}
\hline & \multicolumn{4}{|c|}{ Group } & \multirow[b]{2}{*}{$\mathrm{P}$ value } \\
\hline & $\begin{array}{c}A \\
\text { (freestanding root) }\end{array}$ & $\begin{array}{c}B \\
\text { (inclusion) }\end{array}$ & $\begin{array}{c}C \\
\text { (subcoronary) }\end{array}$ & $\begin{array}{c}D \\
\text { (control subjects) }\end{array}$ & \\
\hline Patients (n) & 8 & 14 & 84 & 10 & \\
\hline \multicolumn{6}{|c|}{ Dimensions (mm; mean $\pm \mathrm{SD}$; median) } \\
\hline ANN min & $24.4 \pm 3.9(23.3)$ & $23.2 \pm 2.6(23.4)$ & $22.2 \pm 3.1(22.0)$ & $21.4 \pm 2.2(21.9)$ & $>.2$ \\
\hline Anulus max & $27.4 \pm 4.7(28.9)$ & $25.1 \pm 3.1(25.0)$ & $24.1 \pm 3.2(23.5)$ & $23.7 \pm 1.9(23.8)$ & $>.2$ \\
\hline Sinus min & $39.0 \pm 8.3(38.1)$ & $30.5 \pm 4.2(29.4)$ & $30.4 \pm 3.9(30.4)$ & $30.3 \pm 4.0(30.5)$ & $.03\left({ }^{*} \mathrm{~A}>\mathrm{C}\right)$ \\
\hline Sinus max & $41.3 \pm 8.6(39.8)$ & $32.8 \pm 4.7(31.8)$ & $32.6 \pm 4.0(33.1)$ & $32.2 \pm 4.2(32.7)$ & $.03\left({ }^{*} \mathrm{~A}>\mathrm{C}\right)$ \\
\hline Supra-aortic ridge min & $32.1 \pm 8.2(30.2)$ & $27.6 \pm 4.1(26.1)$ & $26.5 \pm 3.3(26.7)$ & $25.1 \pm 2.4(25.4)$ & .17 \\
\hline Supra-aortic ridge max & $34.7 \pm 8.6(33.2)$ & $30.0 \pm 4.5(28.4)$ & $28.5 \pm 3.5(28.4)$ & $26.8 \pm 2.8(27.9)$ & .13 \\
\hline \multicolumn{6}{|c|}{ Percent change in radius $(\%$; mean $\pm \mathrm{SD}$; median $)$} \\
\hline Anulus & $11.5 \pm 5.8(10.2)$ & $7.6 \pm 3.1(6.7)$ & $8.4 \pm 3.2(8.1)$ & $10.4 \pm 3.9(10.0)$ & .13 \\
\hline Sinus & $5.8 \pm 1.8(6.0)$ & $7.3 \pm 1.8(6.6)$ & $7.0 \pm 2.4(6.8)$ & $6.1 \pm 1.5(6.3)$ & $>.2$ \\
\hline Supra-aortic ridge & $7.7 \pm 1.2(7.7)$ & $8.3 \pm 2.1(8.3)$ & $7.4 \pm 2.9(7.2)$ & $6.5 \pm 3.0(6.9)$ & $>.2$ \\
\hline \multicolumn{6}{|c|}{ Pressure strain elastic modulus $\left(\mathrm{g} / \mathrm{cm}^{2} ;\right.$ mean $\pm \mathrm{SD} ;[$ median] $)$} \\
\hline Anulus & $680 \pm 561(520)$ & $898 \pm 644(744)$ & $728 \pm 344(657)$ & $542 \pm 283(513)$ & .10 \\
\hline Sinus & $1106 \pm 415(920)$ & $798 \pm 210(775)$ & $865 \pm 365(802)$ & $833 \pm 261(903)$ & $>.2$ \\
\hline Supra-aortic ridge & $837 \pm 385(623)$ & $664 \pm 175(715)$ & $879 \pm 694(763)$ & $925 \pm 523(766)$ & $>.2$ \\
\hline
\end{tabular}

Note: re: Percent change in radius and pressure strain elastic modulus: there were no significant differences between groups and control subjects. $\min$, Minimum dimension; $\max$, maximum dimension.

${ }^{*} P<.05$, other possible pair comparisons were nonsignificant.

after the operation. However, there was a wide variation in diameters, with only 2 patients above the normal limits (Fig 4). At supra-aortic ridge and anulus level, the diameters were not significantly enlarged. This difference in the location of root dilatation may be explained by the fact that at supra-aortic ridge level, a possible enlargement is restricted by the suture line and the ascending aorta and at anulus level by the reinforcing effect of the aortic valve anulus. Only at the sinus level is there no constraining external tissue as dilatation inhibitor. It remains unclear whether, in our 2 patients, the dilatation with a diameter around $50 \mathrm{~mm}$ was promoted by tissue disorders, as suggested by David and colleagues, ${ }^{16}$ or by the thickness and structural composition (collagenous and elastic fibers) of the wall of the pulmonary artery at the time of the operation. On the other hand, the operative technique (ie, excision of fat and fascia) may have some influence on the process of dilatation. ${ }^{9}$

An important issue for the determination of the role of the freestanding root technique in the Ross procedure is the behavior of the diameter over time. Because of the small number of patients with a freestanding root, the lack of serial echocardiographic-determined diameters at this special level, and the fact that 8 of 9 patients of the freestanding root group underwent operation in a close time frame between 1990 and 1993, the influence of the time interval between operation and restudy cannot be judged sufficiently. Nevertheless, a diameter over $50 \mathrm{~mm}$ at sinus level in patients without the Ross procedure is considered aneurysmatic. Whether the same criteria hold true for the freestanding autograft remains to be established by close follow-up studies.

In the patient with the largest diameter at sinus level $(55 \mathrm{~mm})$, there was a mild aortic insufficiency that was constant over the years, which indicates that the width of the root at sinus level probably does not influence valve competence. This is supported by the findings of Elkins ${ }^{17}$ who reported of root dilatation in children without development of aortic regurgitation. In contrast David and colleagues ${ }^{16}$ pointed out that, in adults, the dilatation of the whole root has the potential to develop aortic regurgitation.

We did not find enlarged dimensions after the inclusion and subcoronary techniques, which indicated the dilatation protecting effect of the patients' own root tissue. Other methods for reinforcing the freestanding autograft such as an absorbable mesh ${ }^{18}$ or glutaraldehyde-fixed bovine pericardium ${ }^{19}$ have been reported.

Regarding aortic regurgitation, we found a slightly increased incidence of mild aortic regurgitation in the subcoronary group $(32 \%)$ when compared with the inclusion technique that also preserves the anatomical integrity of the pulmonary autograft similar to the freestanding root. David and colleagues ${ }^{16}$ reported a very low incidence of mild aortic regurgitation after the freestanding root technique, which supports the concept of preserving the normal anatomy. To decrease the incidence of regurgitation after the subcoronary tech- 


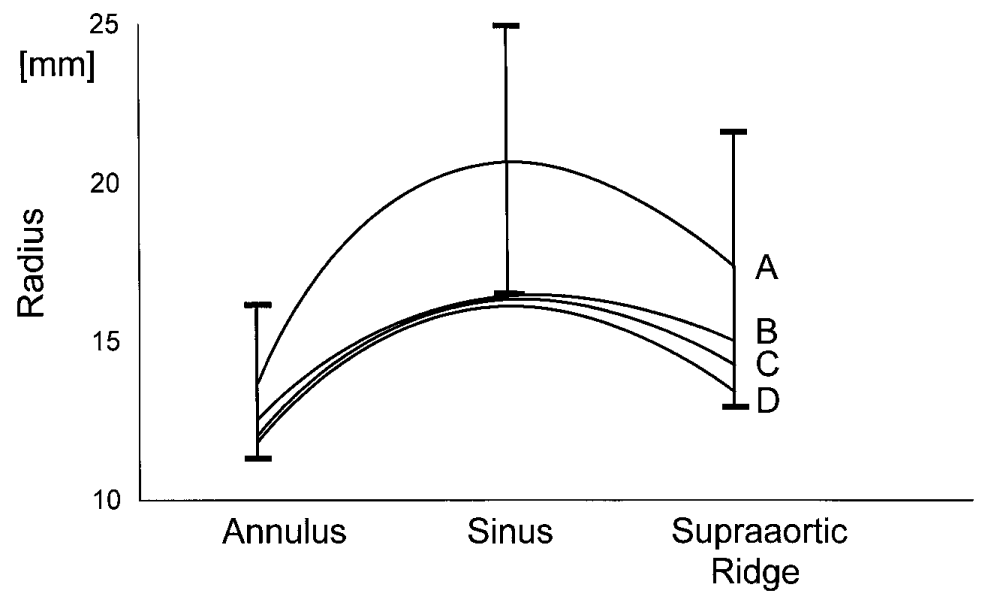

Site of Measurement

Fig 2. Diagram of maximum aortic root dimensions of the different anatomical levels. Note the significantly increased diameter of the freestanding root technique at sinus level. (A) Group A, freestanding root technique, $(B)$ group $\mathrm{B}$, inclusion technique, $(C)$ group $\mathrm{C}$, subcoronary technique, and $(D)$ group $\mathrm{D}$, control subjects.

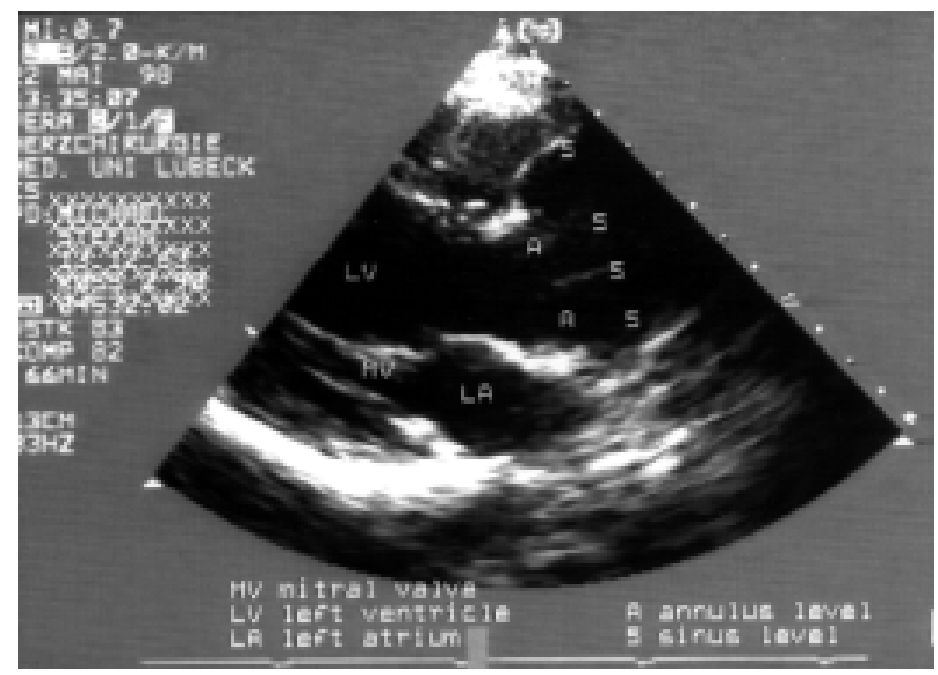

Fig 3. Echocardiographic appearance of the longitudinal view of the aortic root shows the increased sinus diameter of a patient with a freestanding root.

nique, more exact matching of the autograft and the aortic root is probably necessary, as reported by Joyce and colleagues. ${ }^{20}$ Following more stringent rules for matching the dimensions at the sinotubular junction of the native aortic and the pulmonary root, we reduced the incidence of grade I aortic valve regurgitation to $20 \%$ in the last 20 patients.

An important factor of the sophisticated dynamics of the aortic valve relates to the distensibility of the aortic root. Thubrikar and colleagues ${ }^{21,22}$ and Sievers and col- leagues ${ }^{23}$ observed that the semilunar valve-opening mechanism occurs in concert with root expansion during the beginning of systole. This interrelation between supra-aortic ridge displacement and leaflet motion greatly determines the stress on the leaflets. ${ }^{24,25} \mathrm{We}$ found no significant differences in the distensibility parameters at the supra-aortic ridge level between the operative techniques and control subjects. These normal values of distensibility probably decrease leaflet stresses $^{24,25}$ and thus serve to contribute to the durabil- 


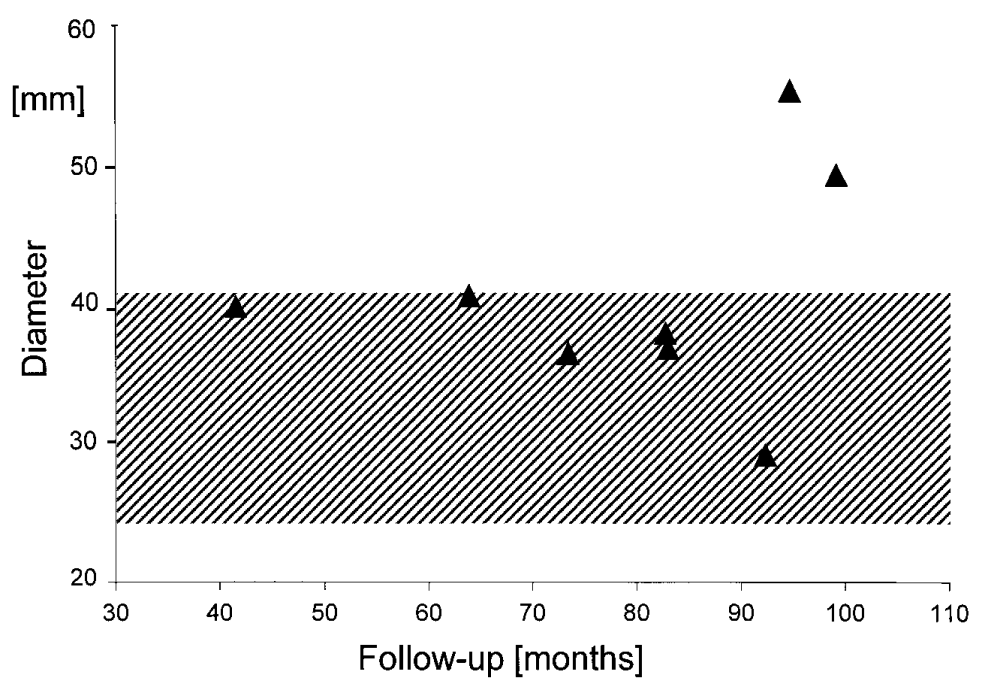

Fig 4. Diagram of the maximum diameter at sinus level of group A (freestanding root) in relation to the duration of follow-up compared with control subjects (shaded area; mean $\pm 2 \mathrm{SD}$ ). There was no obvious relation between the parameters.

ity of valve function. In addition these data also provide some evidence that the inclusion technique does not lead to increased stiffness by the double wall as suggested by Ross. ${ }^{9}$ Theoretically, the sudden increase of systemic pressure on the pulmonary autograft should have some influence on aortic root distensibility, especially in the freestanding root. However, we did not find a significantly reduced distensibility in this group, although the pressure strain elastic modulus at sinus level in group A was slightly increased, indicating a somewhat reduced distensibility at this level only. Whether this is related to the disintegration of elastic fibers remains to be evaluated by histologic examinations. Sievers and colleagues ${ }^{26}$ demonstrated in children with 2-stage anatomical correction that elastic fibers were damaged by acute pressure increase in the pulmonary root after banding.

\section{Limitations of the study}

This study has several limitations. First, it could be argued that the resolution of the ultrasound technique is not sufficient to define accurate instantaneous movements of the aortic root. The ultrasound technique used in this study operates at a $900-\mathrm{Hz}$ sampling frequency and provides an interval between 2 consecutive signals of $1.1 \mathrm{~ms}$, which we believe to be adequate to define aortic root dimensions. In addition the technique that we used provided reproducible results with a range of variation of repetitive measured diameters up to $5.6 \%$. This could have some impact on the distensibility data. Probably more dis- criminative methods for diameter determination will serve to further investigate the behavior of the cyclic changes of the aortic root.

Second, another limitation relates to the significantly longer period of follow-up in group A (freestanding root technique), which may have some influence on the time course of aortic root dilatation. It is, however, unlikely that significant dilatation occurs in patients with subcoronary and inclusion techniques because their native aortic root is preserved.

Third, serial echocardiograms would be helpful to evaluate the impact of time on root size and valve function, which has not been performed in this study.

Finally, this study was not randomized. However, only 1 operative technique was performed at 1 time interval each. Thus, a bias of assigning patients to a special technique is reduced.

In conclusion, this study provides some evidence that all 3 techniques of the Ross procedure (the freestanding root, the inclusion, and the subcoronary techniques) provide excellent hemodynamics in most patients and that the freestanding root in the Ross procedure may include the potential problem of enlarged diameters, especially at the sinus level, in contrast to the inclusion and subcoronary techniques, without interfering with valve function. The elastic modulus was comparable between the 3 operative techniques, with the double wall in the inclusion technique having no impact on distensibility. These findings deserve further evaluation and probably give some impact on the operative procedure and follow-up investigations. 


\section{REFERENCES}

1. Lower RR, Stofer CR, Shumway NE. A study of pulmonary valve autotransplantation. Surgery 1960;48:1090-100.

2. Pillsbury RC, Shumway NE. Replacement of the aortic valve with the autologous pulmonic valve. Surg Forum 1966;17:176-7.

3. Ross DN. Replacement of aortic and mitral valves with pulmonary autograft. Lancet 1967;2:956-8.

4. Stelzer P, Jones DJ, Elkins RC. Aortic freestanding root with pulmonary autograft. Circulation 1989;80(suppl):209-13.

5. Ross DN. Replacement of the aortic valve with a pulmonary autograft: the "Switch" operation. Ann Thorac Surg 1991;52:1346-50.

6. Stelzer P, Elkins RC. Pulmonary autograft: an American experience. J Card Surg 1987;37:429-33.

7. Ross D, Jackson M, Davies J. Pulmonary autograft aortic valve replacement: long-term results. J Card Surg 1991;6(suppl):529-33.

8. Ross DN, Jackson M, Davies J. The pulmonary autograft: a permanent aortic valve. Eur J Cardiothorac Surg 1992;6:113-7.

9. Ross D. The pulmonary autograft: history and basic techniques. Semin Thorac Cardiovasc Surg 1996;8:350-7.

10. Roman MJ, Devereux RB, Kramer-Fox R, O'Loughlin J. Two dimensional echocardiographic aortic root dimensions in normal children and adults. Am J Cardiol 1989;64:507-12.

11. Wiegers SE, Plappert T, St John Sutton MG. Echocardiography of the aortic valve. In: Izzat MB, Sanderson JE, St John Sutton MG, editors. Echocardiography in adult cardiac surgery. 1st ed. Oxford (UK): Isis Medical Media Ltd; 1999. p. 97-116.

12. Jarmakani JM, Graham TP, Benson DW, Canent RV, Greenfield JC. In vivo pressure-radius relationships of the pulmonary artery in children with congenital heart disease. Circulation 1971;43:585-92.

13. Abt K. Descriptive data analysis: a concept between confirmatory and exploratory data analysis. Methods Inf Med 1987;26:77-88.

14. Chambers JC, Somerville J, Stone S, Ross DN. Pulmonary autograft procedure for aortic valve disease. Circulation 1996;7:2206-14.

15. Sievers HH, Leyh R, Loose R, Guha M, Petry A, Bernhard A. Time course of dimension and function of the autologous pul- monary root in the aortic position. J Thorac Cardiovasc Surg 1993;105:127-30.

16. David TE, Omran A, Webb G, Rakowski H, Armstrong S, Sun Z. Geometric mismatch of the aortic and pulmonary roots causes aortic insufficiency after the Ross procedure. J Thorac Cardiovasc Surg 1996;112:1231-9.

17. Elkins RC. Pulmonary autograft: The optimal substitute for the aortic valve? N Engl J Med 1994;330:59-60.

18. Moritz A, Domanig E, Marx M, Moidl R, Simon P, Laufer G, et al. Pulmonary autograft valve replacement in the dilated and asymmetric aortic root. Eur J Cardiothorac Surg 1993;7:405-8.

19. Pacifico AD, Kirklin JK, McGiffin DC, Matter GJ, Nanda NC, Diethelm AG. The Ross operation: early echocardiographic comparison of different operative techniques. J Heart Valve Dis 1994;3:365-70.

20. Joyce F, Tingleff J, Petterson G. A systematic technical approach to the Ross operation. J Heart Valve Dis 1996;5:391-403.

21. Thubrikar MJ, Heckman JL, Nolan SP. High speed cine-radiographic study of aortic valve leaflet motion. J Heart Valve Dis 1993;2:653-61.

22. Thubrikar M, Bosher LP, Nolan SP. The mechanism of opening of the aortic valve. J Thorac Cardiovasc Surg 1979;40:863-70.

23. Sievers HH, Storde U, Rohwedder EB, Lange PE, Onnasch DGW, Heintzen PH, et al. Superior function of a bicuspid over a monocuspid patch for reconstruction of a hypoplastic pulmonary root in pigs. J Thorac Cardiovasc Surg 1993;105:58090.

24. Thubrikar M, Skinner JR, Aouad J, Finkelmeier BA, Nolan SP. Analysis of the design and dynamics of aortic bioprostheses in vivo. J Thorac Cardiovasc Surg 1982;84:282-90.

25. Thubrikar MJ, Nolan SP, Aoud J, Deck JD. Stress sharing between the sinus and leaflets of canine aortic valves. Ann Thorac Surg 1986;42:434-40.

26. Sievers HH, Lange PE, Arensman FW, Radley-Smith R, Yacoub $\mathrm{MH}$, Harms D, et al. Influence of two-stage anatomic correction on size and distensibility of the anatomic pulmonary functional aortic root in patients with simple transposition of the great arteries. Circulation 1984;70:202-8. 